\title{
Clinical outcome and survival following microsurgical reconstruction in patients with oral and oropharyngeal
} cancer

\author{
Shems Al-Hayder ${ }^{* 1}$, Jens J. Elberg ${ }^{2}$ and Birgitte Charabi ${ }^{1}$ \\ ${ }^{1}$ Department of Otorhinolaryngology, Head and Neck Surgery, and Audiology, Rigshospitalet, Copenhagen University Hospital, Blegdamsvej 9, 2100 København \\ $\varnothing$, Denmark \\ ${ }^{2}$ Department of Plastic Surgery, Breast Surgery, and Burns Treatment, Rigshospitalet, Copenhagen University Hospital, Blegdamsvej 9, 2100 København $\varnothing$, \\ Denmark
}

\begin{abstract}
Objective: To determine clinical outcomes and survival following resection of oral or oropharyngeal cancer combined with microsurgical reconstruction

Methods: Retrospective review of medical records. All patients undergoing tumour resection and primary reconstruction by fibula free flap or radial forearm free flap between 2001 and 2012 were included.

Results: The study comprised 60 patients. Thirty-six patients (60.0\%) developed early complications including 14 wound dehiscences (23.3\%), 6 haemorrhages (10.0\%), 6 fistulations (10.0\%), 5 seromas (8.3\%), and 5 wound infections (8.3\%). Free flap success rate was $93.3 \%$. Mandibular osteoradionecrosis due to radiotherapy occurred as late complication in 10 patients (16.7\%). 5-year crude survival rate was 44\%, 36\%, and 28\% for stage II, III, and IV, respectively. 5-year disease-specific survival rate was $63 \%, 50 \%$, and $46 \%$ for stage II, III, and IV, respectively.

Conclusion: Fibula free flap and radial forearm free flap provide high safety and reliability with low incidence of free flap failure and an acceptable level of complications as well as long-term survival. Hopefully, the findings will be useful to clinicians during patient counselling concerning expected recovery in terms of short- and longterm complications and survival following ablative surgery in the oral cavity and oropharynx and microsurgical reconstruction.
\end{abstract}

\section{Introduction}

The management of oral and oropharyngeal cancer has undergone radical changes in the last few decades with a growing trend toward improving cosmesis and patient body image after surgery. With the advent of microsurgical free tissue transfer techniques, immediate reconstruction of form and function has become possible, while allowing extensive tumour resections. To date, numerous studies have demonstrated that, when dealing with composite or large defects, microsurgical reconstructive techniques can greatly improve postoperative functional and aesthetic results $[1,2]$, while preserving a satisfactory health-related quality of life [3-5].

The fasciocutaneous radial forearm free flap has become the preferred approach for reconstruction of extensive soft tissue defects in the oral cavity and oropharynx, and the osteocutaneous fibula free flap for bony reconstruction of oromandibular defects. Microsurgical free flap reconstruction is a safe procedure associated with high success rates ranging from 96 to 98 percent and acceptably low donor site morbidity [6-10].

The aim of the present study is to evaluate clinical outcomes and survival in patients undergoing resection of oral and oropharyngeal cancer and primary reconstruction with a radial forearm free flap or fibula free flap.

\section{Materials and methods}

The medical records of all patients undergoing primary microsurgical reconstruction by a radial forearm free flap or fibula free flap due to oral or oropharyngeal cancer at Rigshospitalet, Copenhagen University Hospital, between September 2001 and July 2012 were reviewed retrospectively. All surgical procedures were performed by an interdisciplinary team of head and neck surgeons and microvascular surgeons.

The patient records were obtained from a database established by the Department of Plastic Surgery, Breast Surgery, and Burns Treatment at Rigshospitalet, Copenhagen University Hospital.

Data collected from the medical records included tumour and treatment characteristics, postoperative complications, and survival.

Correspondence to: Dr. Shems Al-Hayder, Department of Otorhinolaryngology, Head and Neck Surgery, and Audiology, Rigshospitalet, Copenhagen University Hospital, Blegdamsvej 9, 2100 København Ø, Denmark; Tel: +4538681368; Fax: +4535454526; E-mail: shems.al-hayder@regionh.dk

Key words: Free tissue flaps, head and neck neoplasms, postoperative complications, survival

Received: August 22, 2016; Accepted: September 30, 2016; Published: October 04, 2016 
Postoperative complications were categorized as recipient site, donor site, and general complications, and further divided into early and late complications. Early complications were classified as occurring during the initial hospitalization and requiring intervention. Late complications were defined as events necessitating further treatment.

\section{Results}

\section{Statistical analysis}

The presentation was primarily descriptive. Survival was calculated from the date of surgery to the date of death. Crude survival and diseasespecific survival was assessed by Kaplan-Meier analysis. Statistical analyses were done with SPSS software, version 19 for Windows (SPSS Inc., Chicago IL).

\section{Recruitment of the study population}

A total of 61 patients underwent primary reconstruction with a radial forearm free flap or fibula free flap following resection of oral or oropharyngeal cancer. One patient was excluded secondarily due to lack of clinical documentation, resulting in a sample of 60 patients.

\section{Study population characteristics}

Study population included 45 men (75.0\%) and 15 women (25.0\%) with a median age of 59 years, range 39 to 82 years. The clinical characteristics are listed in Table 1.

The oral and oropharyngeal defects were reconstructed using a radial forearm free flap in 34 patients $(56.7 \%)$ and a fibula free flap in 26 patients (43.3\%). Four patients underwent reconstruction with a fibula free flap and an anterolateral thigh free flap simultaneously, and one patient was reconstructed with a fibula free flap and a pectoralis major pedicled flap. Unilateral neck dissection was performed in 36 cases $(60.0 \%)$ and bilateral neck dissection in six cases $(10.0 \%)$. Mandibulectomy was carried out as marginal in 14 cases $(23.3 \%)$ and segmental in 32 cases (53.3\%). Twenty-one patients $(35.0 \%)$ had a history of previous radiotherapy. Radiotherapy was conducted preoperatively in one patient (1.7\%) and postoperatively in 32 patients (53.3\%). Median irradiation dose was $66 \mathrm{~Gy}$, range 30 to $68 \mathrm{~Gy}$. Four patients $(6.7 \%)$ received concomitant chemotherapy.

\section{Clinical outcome}

Following reconstruction, patients were hospitalized for a median of 16 days, range 6 to 95 days. Most patients returned to a normal or modified oral diet, depending on their preoperative condition, however four patients became gastrostomy tube dependent postoperatively (6.7\%). Forty-five patients (75.0\%) were tracheostomized to ensure the persistence of the airways after the surgical procedure, and they were all except in one case successfully decannulated.

Thirty-six patients experienced early complications (60.0\%), while late complications occurred in 23 patients (38.3\%). Fifteen patients (25.0\%) developed both early and late complications. Only 17 patients (28.3\%) did not develop postoperative complications at all.

Early complications at the recipient site occurred in 22 patients (36.7\%) including 6 haemorrhages (10.0\%), 6 orocutaneous fistulations (10.0\%), 5 seromas $(8.3 \%), 5$ wound infections $(8.3 \%)$ and 2 wound dehiscences (3.3\%). Resurgery was necessary in two cases of fistulation and dehiscence, while the other complications were treated conservatively. In four patients the radial forearm free flap was lost due to vascular complications (6.7\%), and a secondary reconstruction was successfully managed with another radial forearm free flap in all cases.
Table 1. Clinical characteristics of the 60 patients.

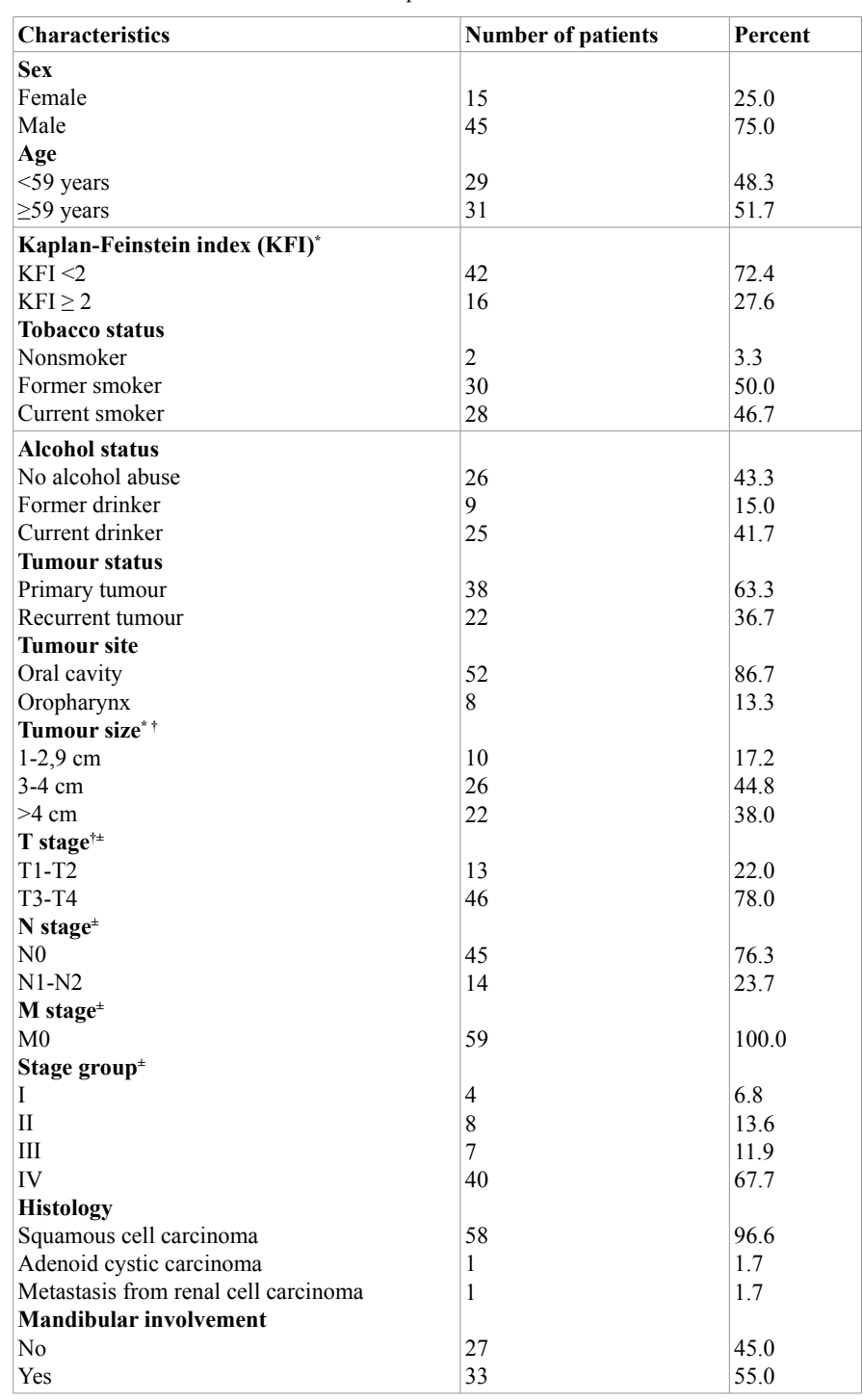

"58 patients with known comorbidity and tumour size

†Tumour size and $\mathrm{T}$ stage are from the time of primary diagnosis.

${ }^{ \pm}$One patient with renal cell carcinoma was excluded from the TNM staging.

Three patients, reconstructed with a radial forearm free flap, had partial flap necrosis $(5.0 \%)$ but only one patient required a surgical revision. Thus, the overall free flap success rate was 93.3 percent.

Early donor site complications were registered in 20 patients (33.3\%) consisting of 14 wound dehiscence (23.3\%), 5 wound infections (8.3\%), 2 haematomas (3.3\%), and one partial loss of the skin graft (1.7\%). One case of haematoma and partial loss of skin graft prompted surgical revision. The remaining complications were transitory and responded well to conservative treatment.

The most prevalent general complication was pneumonia (13.3\%); which was resolved successfully with intravenous antibiotics.

The majority of late complications included wound dehiscence in 14 cases $(23.3 \%)$, mandibular osteoradionecrosis in 10 cases $(16.7 \%)$, and infected internal fixation in 8 cases (13.3\%). The complications were treated with hyperbaric oxygen therapy (HBO) in one case (1.7\%), surgery in 6 cases (10.0\%), surgery and adjuvant HBO in 7 cases 
(11.7\%), while 11 cases $(18.3 \%)$ received conservative therapy. The characteristics of the postoperative complications in the 60 patients are shown in Table 2.

\section{Survival}

The survival was estimated for 59 patients who met the inclusion criteria with an accessible medical record and a TNM-staging. One patient had metastasis of renal cell carcinoma in the mandible and was thus excluded. The survival rates are presented in Table 3.

\section{Discussion}

The high success rate $(93.3 \%)$ achieved in this study confirms the reliability of microvascular procedures in this specific patient population. This is in agreement with the results of other studies concerning reconstruction with a radial forearm free flap or fibula free flap in oral and oropharyngeal cancer, reporting rates above $90 \%$ $[4,6,9,10]$. It should be noted that both the total and partial free flap losses occurred in patients reconstructed with a radial forearm free flap. However, previous studies have found that the risk of free flap failure in the head and neck region is lower for soft tissue reconstruction compared to osseous reconstruction. The discrepancy may be explained by the fact that most of these patients had a history of previous surgery

Table 2. Characteristics of the postoperative complications of the 60 patients.

\begin{tabular}{|l|c|c|}
\hline Postoperative complications & Number of patients & Percent \\
\hline Early & 6 & 10.0 \\
Recipient site & 6 & 10.0 \\
Haemorrhage & 5 & 8.3 \\
Fistula & 5 & 8.3 \\
Wound infection & 2 & 3.3 \\
Seroma & & \\
Wound dehiscence & 3 & 5.0 \\
Flap necrosis & 4 & 6.7 \\
Partial & & \\
Total & & 23.3 \\
\hline Donor site & 14 & 8.3 \\
Wound dehiscence & 5 & 3.3 \\
Wound infection & 2 & 1.7 \\
Haematoma & 1 & 13.3 \\
\hline Partial skin graft necrosis & & \\
General & 8 & 23.3 \\
\hline Pneumonia & 14 & 16.7 \\
\hline Late & & 13.3 \\
Wound dehiscence & 10 & 1.7 \\
\hline Mandibular osteoradionecrosis & 8 & 1.7 \\
\hline Infected internal fixation & 1 & 1.7 \\
\hline Intraoral abscess & 1 & \\
Fractured internal fixation & 1 & \\
Pseudoarthrosis & & \\
\hline
\end{tabular}

*All occurring at recipient site except for four wound dehiscences at donor site.

Table 3. Survival rates related to stage distribution of the 59 patients.

\begin{tabular}{|l|c|c|}
\hline Survival & $\begin{array}{c}\text { 3-year rate } \\
\text { Percent }\end{array}$ & $\begin{array}{c}\text { 5-year rate } \\
\text { Percent }\end{array}$ \\
\hline Crude survival $^{\star}$ & & \\
Stage I & 25 & 25 \\
Stage II & 44 & 44 \\
Stage III & 36 & 36 \\
Stage IV & 42 & 28 \\
\hline Disease-specific survival & & \\
Stage I & 25 & 25 \\
Stage II & 63 & 63 \\
Stage III & 50 & 50 \\
Stage IV & 57 & 46 \\
\hline
\end{tabular}

"One patient with metastasis from renal cell carcinoma was excluded due to lack of TNM staging. for a head and neck cancer, which is a well-recognized factor associated with postoperative complications, including free flap failure $[11,12]$.

In our investigation, the complication rates are higher than those documented in previous papers [4,6]. Early complications were observed in approximately one third of the patients, in which $36.7 \%$ occurred at the recipient site and $33.3 \%$ at the donor site. However, only 8 patients $(13.3 \%)$ underwent resurgery due to complications, indicating that the early recipient and donor site complications were generally not severe. This corresponds well with the findings of Gonzalez-Garcia et al. [9].

Thirty-five percent of the patients have received radiotherapy in the head and neck region previously. To date, the literature regarding the relationship between postoperative complications and prior radiotherapy has been inconsistent. Whereas some studies have reported an increased complication rate $[11,13]$, other investigations have been unable to document such a statistically significant association $[12,14]$.

Additionally, findings suggest that cigarette smoking leads to a higher rate of postoperative complications [15], while other series have not been able to support this association $[14,16]$.

In this series, 16.7 percent of the irradiated patients have developed mandibular osteoradionecrosis, which is a well-known arduous late complication following radiotherapy to the head and neck region [17].

The radial forearm free flap is still a very versatile flap for soft tissue reconstruction in oral and oropharyngeal cancer, however, the anterolateral thigh flap, has shown to be a good alternative, and has become increasingly popular due to lower donor site morbidity. In smaller defects local flaps such as the genioglossal flap, facial artery musculomucosal flap, and buccal fat pad have become the preferred method of soft tissue reconstruction in the oral cavity whenever possible. This is mainly due to the cost-saving benefits and lower donor site complications. However, the fibula free flap is still the preferred method of choice in terms of mandibular reconstruction.

The present study demonstrates acceptable 5-year crude survival rates for patients with tumour stage II, III and IV. Furthermore, the 5-year disease-specific survival rates for patients with locally advanced cancer are favourable. This is particularly encouraging when considering that a third of the population had a recurrent tumour. These findings are in accordance with similar published studies in which excellent disease-specific survival rates up to $60 \%$ have been achieved for patients with stage II, III and IV cancer $[6,14]$.

The crude survival rates are comparable to recent oncological studies of patients with stage III and IV head and neck cancer receiving radiotherapy or chemoradiotherapy $[18,19]$.

Interestingly, our findings show that patients with tumour stage I have less favourable survival rates compared to the other tumour stages. This is explained by the fact that the small group of patients, diagnosed with $\mathrm{T} 1$, had a recurrent tumour or tumour progression from the time of diagnosis and staging to the time of surgery. Postoperatively, they continued their abuse of tobacco and alcohol and perished from a recurrent or second head and neck tumour.

\section{Conclusion}

In conclusion, the current study confirms the high reliability of reconstruction with a radial forearm free flap and fibula free flap with low incidence of free flap failure and an acceptable level of severe 
complications as well as long-term survival.

Hopefully, the findings will be useful to clinicians during patient counselling concerning expected recovery in terms of short- and longterm complications and survival following oral and oropharyngeal tumour resection and microsurgical reconstruction.

\section{Ethical standards}

Ethical approval and informed consent were not required according to Danish regulations. The study was approved by the Danish Data Protection Agency (No. 2014-41-3568).

\section{References}

1. Hölzle F, Kesting MR, Hölzle G, Watola A, Loeffelbein DJ, et al. (2007) Clinical outcome and patient satisfaction after mandibular reconstruction with free fibula flaps. Int J Oral Maxillofac Surg 36: 802-806. [Crossref]

2. Khariwala SS, Vivek PP, Lorenz RR, Esclamado RM, Wood B, et al. (2007) Swallowing outcomes after microvascular head and neck reconstruction: a prospective review of 191 cases. Laryngoscope 117: 1359-1363. [Crossref]

3. Borggreven PA, Aaronson NK, Verdonck-de Leeuw IM, Muller MJ, Heiligers ML, Bree RD (2007) Quality of life after surgical treatment for oral and oropharyngeal cancer: a prospective longitudinal assessment of patients reconstructed by a microvascular flap. Oral Oncol 43:1034-1042. [Crossref]

4. Rhemrev R, Rakhorst HA, Zuidam JM, Mureau MAM, Hovius SER, Hofer SOP (2007) Long-term functional outcome and satisfaction after radial forearm free flap reconstructions of intraoral malignancy resections. J Plast Reconstr Aesthet Surg 60: 588-592. [Crossref]

5. Villaret AB, Cappiello J, Piazza C, Pedruzzi B, Nicolai P (2008) Quality of life in patients treated for cancer of the oral cavity requiring reconstruction: a prospective study. Acta Otorhinolaryngol Ital 28: 120-125. [Crossref]

6. Bozec A, Poissonnet G, Chamorey E, Laout C, Vallicioni J, et al. (2009) Radical ablative surgery and radial forearm free flap (RFFF) reconstruction for patients with oral or oropharyngeal cancer: postoperative outcomes and oncologic and functional results. Acta Otolaryngol 129: 681-687. [Crossref]

7. González-García R, Rodríguez-Campo FJ, Naval-Gías L, Sastre-Pérez J, MuñozGuerra MF, et al. (2007) Radial forearm free flap for reconstruction of the oral cavity: clinical experience in 55 cases. Oral Surg Oral Med Oral Pathol Oral Radiol Endod 104: 29-37. [Crossref]
8. Smith GI, O'Brien CJ, Choy ET, Andruchow JL, Gao K (2005) Clinical outcome and technical aspects of 263 radial forearm free flaps used in reconstruction of the oral cavity. Br J Oral Maxillofac Surg 43: 199-204. [Crossref]

9. Gonzalez-Garcia R, Naval-Gias L, Rodriguez-Campo FJ, Roman-Romero L (2009) Reconstruction of oromandibular defects by vascularized free flaps: the radial forearm free flap and fibular free flap as major donor sites. J Oral Maxillofac Surg 67: 14731477. [Crossref]

10. López-Arcas JM, Arias J, Del Castillo JL, Burgueño M, Navarro I, et al. (2010) The fibula osteomyocutaneous flap for mandible reconstruction: a 15 -year experience. $J$ Oral Maxillofac Surg 68: 2377-2384. [Crossref]

11. Dassonville O, Poissonnet G, Chamorey E, Vallicioni J, Demard F, et al. (2008) Head and neck reconstruction with free flaps: a report on 213 cases. Eur Arch Otorhinolaryngol 265: 85-95. [Crossref]

12. Suh JD, Sercarz JA, Abemayor E, Calcaterra TC, Rawnsley JD, et al. (2004) Analysis of outcome and complications in 400 cases of microvascular head and neck reconstruction. Arch Otolaryngol Head Neck Surg 130: 962-966. [Crossref]

13. Singh B, Cordeiro PG, Santamaria E, Shaha AR, Pfister DG, et al. (1999) Factors associated with complications in microvascular reconstruction of head and neck defects. Plast Reconstr Surg 103: 403-411. [Crossref]

14. Zafereo ME, Weber RS, Lewin JS, Roberts DB, Hanasono MM (2010) Complications and functional outcomes following complex oropharyngeal reconstruction. Head Neck 32: 1003-1011. [Crossref]

15. Haughey BH, Wilson E, Kluwe L, Piccirillo J, Fredrickson J, et al. (2001) Free flap reconstruction of the head and neck: analysis of 241 cases. Otolaryngol Head Neck Surg 125: 10-17. [Crossref]

16. Bourget A, Chang JT, Wu DB, Chang CJ, Wei FC (2011) Free flap reconstruction in the head and neck region following radiotherapy: a cohort study identifying negative outcome predictors. Plast Reconstr Surg 127: 1901-1908. [Crossref]

17. Reuther T, Schuster T, Mende U, Kübler A (2003) Osteoradionecrosis of the jaws as a side effect of radiotherapy of head and neck tumour patients--a report of a thirty year retrospective review. Int J Oral Maxillofac Surg 32: 289-295. [Crossref]

18. Bourhis J, Sire C, Graff P, Grégoire V, Maingon P, et al. (2012) Concomitant chemoradiotherapy versus acceleration of radiotherapy with or without concomitant chemotherapy in locally advanced head and neck carcinoma (GORTEC 99-02): an open-label phase 3 randomised trial. Lancet Oncol 13: 145-153. [Crossref]

19. Beitler JJ, Zhang Q, Fu KK, Trotti A, Spencer SA, Jones CU, et al. (2014) Final results of local-regional control and late toxicity of RTOG 9003: a randomized trial of altered fractionation radiation for locally advanced head and neck cancer. Int J Radiat Oncol Biol Phys 89: 13-20. [Crossref]

Copyright: $(02016$ Al-Hayder S. This is an open-access article distributed under the terms of the Creative Commons Attribution License, which permits unrestricted use, distribution, and reproduction in any medium, provided the original author and source are credited. 